\title{
Early diagnosis of breast and ovarian cancers by body fluids circulating tumor-derived exosomes
}

\author{
Leyla Norouzi-Barough ${ }^{1}$, Amir Asgari Khosro Shahi ${ }^{2}$, Farnoosh Mohebzadeh ${ }^{3}$, Ladan Masoumi ${ }^{3}$, \\ Mohammad Reza Haddadi ${ }^{4,5}$ and Sadegh Shirian $6,7,8^{*}$ (D)
}

\begin{abstract}
Exosomes (EXs) are small extracellular vesicles, a size range of 40-100 nm in diameter, actively secreted by most eukaryotic cells into surrounding body fluids like blood, saliva, urine, bile, breast milk and etc. These endosomalderived vesicles mediate cell-cell communication between various cell populations through transmitting different signaling molecules such as lipids, proteins, and nucleic acids, and participate in a wide range of physiological and pathological body processes. Tumor-derived EXs (TDEs) are vehicles for intercellular communications by transferring bioactive molecules; they deliver oncogenic molecules and contain different molecular cargoes compared to EXs delivered from normal cells, therefore, they can be used as non-invasive invaluable biomarkers for early diagnosis and prognosis of most cancers, including breast and ovarian cancers. Their presence and stability in different types of body fluids highlight them as a suitable diagnostic biomarker for distinguishing various cancer stages. In addition, EXs can predict the therapeutic efficacy of chemotherapy agents and drug resistance in cancer cells, as well as determine the risk of metastasis in different disease stages. In this study, the recent literature on the potential role of TDEs in the diagnosis and prognosis of ovarian and breast cancers is summarized, and then exosome isolation techniques including traditional and new approaches are briefly discussed.
\end{abstract}

Keywords: Exosome, Breast cancer, Ovarian cancer, Biomarker, Diagnosis

\section{Introduction}

Exosomes (EXs) were firstly reported to describe nanosized exfoliated membrane vesicles with $5^{\prime}$-nucleotidase activity and physiologic function [1]. The best definition of EXs is extracellular vesicles which are released by most eukaryotic cells into the surrounding body fluids upon the fusion of multivesicular bodies (MVB) with the plasma membrane [2]. Their presence in different types of body fluids, such as blood, saliva, urine, bile, synovial fluid, breast milk, amniotic liquid, and seminal

*Correspondence: shirian85@gmail.com

${ }^{6}$ Department of Pathology, School of Veterinary Medicine, Shahrekord University, Shahrekord, Iran

Full list of author information is available at the end of the article fluid, indicates their multiple key roles in intercellular communication via transferring both genomic and proteomic materials between cells and subsequently regulating physiological responses [3, 4]. Exosomes are secreted by a variety of normal cells, however, the evidence reveals that secretion of these nano-sized vesicles is more vigorous in pathological conditions, such as tumor cells, as they are detectable in sufficient quantities in specimens of patients with various types of cancer and in supernatant obtained from tumor cells in vitro $[4,5]$. Due to the presence of tumor-specific antigens (TSA) in TDEs in addition to functional proteins, mRNAs, and miRNAs, they are considered as potential candidates for different clinical applications, including cancer diagnosis, prognosis, and treatment [6]. Since isolation of EXs from body 
fluids is relatively easy and considered as a noninvasive approach [7] and due to their specific active cargos, known as the "signature" of the donor cell, which mimic the cellular origin and its physiological and pathophysiological states [8] and considering their ability to provide a protective extracellular vesicle for transporting small RNAs against degradation of RNase, they can be used as worthy diagnostic biomarkers in various diseases, particularly some types of cancer, and can be considered as an ideal specimen for liquid biopsy for early detection of some types of cancers [9]. Here, we describe the application of TDEs for early diagnosis of breast and ovarian cancers.

\section{Breast and ovarian cancers}

Globally, breast cancer (BC) is the most common type of malignity and the leading cause of cancer-related mortality among women. Annually, one in four new cancer cases belongs to female $\mathrm{BC}$. In contrast, although ovarian cancer (OC) is rare, it is the leading cause of gynecological cancer-related mortality worldwide. In fact, ovarian carcinoma is one-tenth as common as $\mathrm{BC}$ but three times more lethal [10-12]. Because of the location of the ovaries within the pelvis, OC progresses asymptomatic in its early stages [13]. Therefore, the high mortality rate of OCs is in part due to late diagnosis and lack of proper screening. Accordingly, OC is known as a silent killer [14, 15]. Both $B C$ and $O C$ are considered as heterogeneous diseases, which are mainly the result of sporadic mutations, and just $5-10 \%$ of cases are attributed to a familial history $[12,16]$. Due to their heterogeneity at both the molecular and clinical levels, current protocols for early detection of breast and OCs are either ineffective or expensive [16]. An appropriate screening method should preferably be efficient, non-invasive, easily executable and evaluable, safe, cost-effective and applicable to all individuals in the community. Thus, the identification of new biomarkers is needed for early diagnosis of $\mathrm{BC}$ and OC.

\section{Characteristics of exosomes and their composition}

Extracellular vesicles (EVs) include EXs and ectosomes (or shedding microvesicles; MVs) which are derived from endosomes and the plasma membrane, respectively. EVs are released by many types of cells and play a critical role in intercellular communication, presumably by serving as vehicles to transport membrane and cytosolic proteins, lipids, DNA (genomic DNA, mtDNA, cDNA) and RNA fragments (mRNAs, miRNAs, lncRNAs) between cells. The third type of EVs is apoptotic bodies (ABs), which are mainly secreted by dying or apoptotic cells and their role in intercellular communication is yet to be clarified [17-20]. EXs are commonly characterized by a size range of $40-100 \mathrm{~nm}$ in diameter [21], a density between 1.13 and $1.19 \mathrm{~g} / \mathrm{mL}$ in a sucrose gradient, and a "saucer-like" or "cup-shaped" morphology when investigated by electron microscopy [22]. The size of EXs is partly influenced by their cellular source and the "cargo hold" of these nanoparticles is approximately $20-90 \mathrm{~nm}$, therefore, it is estimated that the total burden per EXs is probably $\leq 100$ proteins and $\leq 10,000$ nucleotides [23]. Moreover, EXs are characterized by several families of proteins, including tetraspannins (CD82, CD81, CD63, CD9), heat shock proteins (Hsp 90, Hsp70, Hsp60, and Hsc70), membrane trafficking proteins (Rabs, Annexins), proteins involved in MVBs biogenesis (Alix, TSG101, Clathrin), metabolic enzymes (GAPDH, ATPase, PGK1), cytoskeletal proteins (actin, vimentin, cofilin, tublin, talin) as well as lipid rafts, such as cholesterol, flotillins, ceramides, and sphingolipids (Fig. 1) [24, 25]. CD63 and CD9 serve as the most commonly used EXs markers to distinguish them from other vesicles, such as MVs and ABs [26].

\section{Exosomes in cancer malignancy}

The roles of TDEs in the development of cancer are due to their immunostimulatory or immunosuppressive properties and subsequently being involved in maintaining tumor cells survival, growth, and metastasis [22]. Tumor-secreted EXs are powerful intercellular signal mediators between tumor cells and their microenvironment, and their function seems to be dependent on their cargoes and surface biomolecule [27]. The immunological significance of EXs in cancer microenvironment is their potential to modulate the immune system in different ways in a host defense system. TDEs are capable of evading anti-tumor immune responses via different mechanisms [28]. For example, TDEs induce $\mathrm{T}$ cell apoptosis through carrying apoptosis-inducing ligands such as Fas ligand (FasL) and TNF-related apoptosis-inducing ligand (TRAIL), and galectin 9 [29]. On the other hand, they hamper IL-2-dependent activation of $\mathrm{CD}^{+} \mathrm{T}$ cell and natural killer (NK) cells mediated by TGF- $\beta 1$ [29]. Moreover, exosomal programmed death-ligand 1 (PD-L1) can disrupt the activation and infiltration of $\mathrm{T}$ cells into the tumor microenvironment and promotes cancer metastasis and immune escape, but it is not clear whether the role of exosomal PD-L1 is tumor type-dependent or not [30]. Additionally, shedding of MICA/B ligands by tumor cells, as a component of TDEs, prevents NKG2D-mediated killing by $\mathrm{CD} 8^{+} \mathrm{T}$ cells, NK, and $\gamma \delta$ T cells [28]. Proteins and miRNAs carried by TDEs can modulate the expression of immune cells receptors like NKG2D and TLR4, thus suppress immune responses [29]. They also take part in inflammatory cell infiltration, angiogenesis, and transforming 

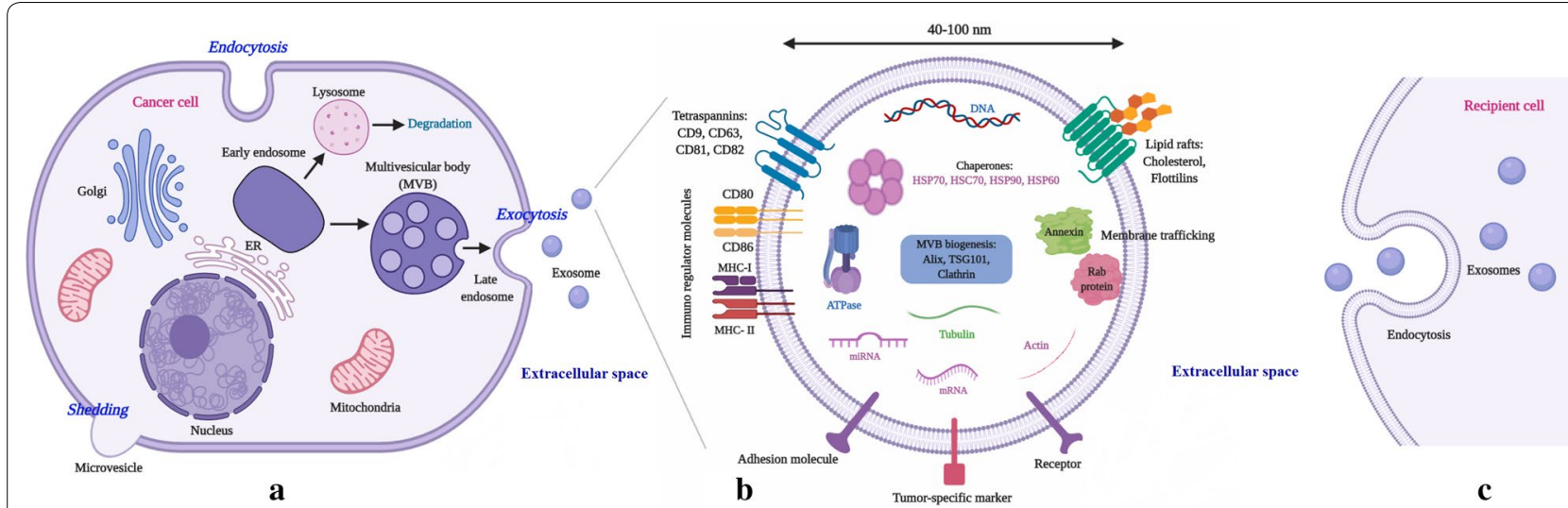

Fig. 1 Biogenesis, structure, release, and uptake of exosomes. a Exosome biogenesis starts with inward budding of the plasma membrane (endocytosis) and the formation of early endosomes. Subsequently, incorporation of cytosolic proteins, lipids, and nucleic acids into the endosomes leads to the formation of multivesicular bodies (MVBs). Finally, MVBs fuse with the plasma membrane through RabGTPases pathway and exosomes are released into the extracellular space. $\mathbf{b}$ Exosomes are enriched by multiple families of proteins, including tetraspannins (CD9, CD63, CD81, CD82), heat shock proteins (Hsc70, Hsp 90, Hsp70, Hsp60), membrane trafficking proteins (Rabs, Annexins), proteins involved in MVBs biogenesis (Alix, TSG101, Clathrin), metabolic enzymes (GAPDH, ATPase, PGK1), cytoskeletal proteins (actin, vimentin, cofilin, tublin, talin), lipid rafts, such as cholesterol, flotillins, ceramides, sphingolipids, DNA, RNA species (mRNAs, miRNAs, IncRNAs) and tumor-specific markers. c Once exosomes are released into the extracellular space, they can interact with recipient cells via direct fusion, endocytosis or receptor-ligand interactions

tumor cells into the more aggressive phenotype, including preparing the pre-metastatic microenvironment, via crosstalk with microenvironment cells, such as epithelial cells, macrophages, endothelial cells, and fibroblasts [31, 32]. Evidence shows that crosstalk between cancer cells-derived EXs and endothelial cells stimulate angiogenesis and metastasis in a hypoxic microenvironment [33]. Tumor exosomal miRNAs, as the main RNA content of EXs, participate in pre-metastatic niche formation and metastasis through interfering with the miRNA profile of target cells at distant organs. For instance, aggressive $\mathrm{BC}$ cells animate less-aggressive tumor cells to initiate metastasis and largely progress by EXs shedding and transfer functional RNAs [34]. Moreover, exosomal oncogenic proteins can promote the migration of tumor cells to the adjacent tissues [35]. As myoferlin present in EXs extracted from breast and pancreatic cancer cells contribute to cancer metastases with promoting exosomal biogenesis and transferring nucleic acids to adjacent cells [35]. Furthermore, EXs, as active transporter nucleic acids and oncogenic proteins to recipient cells, induce cancer drug resistance [36]. In general, EXs are key players in cancer development and progression by interaction with tumor microenvironment components including endothelial, fibroblastic, and immune cells and major tumor-related signaling pathways, such as cancer stemness, angiogenesis, hypoxia driven epithelial-to-mesenchymal transition (EMT), and metastasis [37, 38]. These interactions are needed for cancer growth and accelerate tumor drug resistance [38].

\section{Tumor exosomes as diagnostic biomarkers}

Exosomal biomarkers have been found in different types of biological fluids, such as plasma, urine, blood, saliva, bile, bronchoalveolar lavage fluid, synovial fluid, cerebrospinal fluid, amniotic fluid, semen, breast milk, and malignant ascites [39]. TDEs present higher sensitivity and specificity compared to other body fluids biomarkers [39]. In addition, EXs have several other worthwhile advantages, including their extreme stability (under various conditions, such as cold-storage, freezing, and thawing for up to years), abundance (4000 trillion EXs in the blood of cancer patients versus 2000 trillion EXs in normal human blood), tumor-specificity, and the association of their content with tumor staging and treatment outcome $[6,32]$. Since different types of tumors are characterized by tumor-specific miRNAs or proteins, exosomal cargos reflect the stage and degree of tumor progression [40]. Moreover, the presence of EXs in body fluids, such as blood and urine, highlights them as a non-invasive diagnostic and prognostic biomarker over invasive biopsies [6].

A strong correlation between mRNA and miRNA profiles of tumoral cells and EXs has been confirmed. Since the expression of miRNAs is dysregulated in most cancers, thus, different cancer types present different exosomal miRNAs signatures [7]. For example, microarray analysis revealed the overexpression of five 
miRNAs including hsa-miR-20a-5p, hsa-miR-24-3p, hsa-miR-106a-5p, hsa-miR-891a, and hsa-miR-1908 in EXs derived from patient sera with nasopharyngeal carcinoma compared to EXs from healthy controls [41]. Liu et al. (2017) reported that increased levels of exosomal miR-23b-3p, miR-10b-5p and miR-21-5p predict poor overall survival in non-small-cell lung cancer (NSCLC) patients [42]. Moreover, Sohn et al. (2015) reported that the expression levels of serum exosomal miR-18a, miR221, miR-222, and miR-224 were obviously higher in hepatocellular carcinoma (HCC) patients than those with chronic hepatitis B (CHB) or liver cirrhosis (LC) [43].

On the other hand, EXs are involved in lipid-related pathologies; therefore, the lipid content of EXs may act as another molecular indicator for disease diagnosis and prognosis [8]. To date, based on the free web-based database, ExoCarta (www.exocarta.org), there are 41,860 protein, 4946 mRNA and 1116 lipid entries from 286 studies. Given the above, EXs and their specific cargos, as valuable sources of cell information, may better reflect the cellular processes during the development and progression of malignant tumors.

\section{Ovarian cancer-derived exosomal cargos and their potential role as biomarkers}

The secretion of TDEs was first found in ascites and cyst fluids of OC patients [44]. Afterward, tumor EXs were found in other types of cancers, including melanoma, bladder, prostate, breast, colorectal, and brain cancers [45-47]. Among the mentioned cancers, OC patients are at high risk for mortality due to poor prognosis as well as late diagnosis at advanced stages [48]. Since there is no reliable method for early detection of OC, OC-derived EXs and their molecular cargos are considered as valuable biomarkers due to their large potential in early diagnosis and prognosis [49]. Im et al. (2014) have found that CD24 and epithelial cell surface antigen (EpCAM) are tumor-derived exosomal markers of $\mathrm{OC}$ cells using nano-plasmonic EXs (nPLEX) assay [50]. In another study, Zhao et al. (2016) have measured tumor-derived exosomal markers, CA-125, EpCAM, and CD24, in OC patients plasma using a microfluidic approach (ExoSearch) and reported that combination of these three exosomal markers can provide desirable diagnostic accuracy for early diagnosis of OC [51]. Taylor and Taylor (2008) could distinguish benign OC cases from patients with various stages of $\mathrm{OC}$ using microRNAs profiling EpCAM-positive EXs isolated from the peripheral blood. They have reported eight microRNAs as specific microRNAs defining different stages of OC from benign disease, including miR-141, miR-21, miR-200a, miR-200b, miR200c, miR-214, miR-205 and miR-203 [52]. The results of a study that evaluated serum levels of exosomal miR-373,
miR-200a, miR-200b, and miR-200c in a cohort of 163 patients with epithelial OC indicated that the concentrations of all four exosomal microRNAs in OC patients were higher compared to those in healthy control. Moreover, it has been shown that increased levels of miR-200c and miR-200b were associated with CA125 values and shorter overall survival [53]. Recently, Yoshimura et al. (2018) have reported that the expression level of exosomal miR-99a-5p is significantly up-regulated in sera of OC patients. Their results have indicated that this microRNA promotes cancer cell invasion by affecting neighboring human peritoneal mesothelial cells (HPMCs) via up-regulation of fibronectin and vitronectin. Therefore, serum miR-99a-5p may serve both as a potential detection biomarker and a target for inhibiting OC progression [54].

Szajnik et al. (2014) have revealed that plasma exosomal TGF- $\beta 1$ and melanoma-associated antigen family (MAGE3/6) can be used to distinguish OC patients from those with benign tumors or healthy controls [55]. Li et al. (2009) have found that full-length membrane protein Claudin-4 can be shed from OC cells, therefore, claudin-containing EXs from the peripheral blood of ovarian carcinoma patients may be useful biomarkers for OC detection [56]. Moreover, Keller et al. (2009) have introduced L1CAM, CD24, ADAM10, and EMMPRIN as tumor exosomal biomarkers for early-stage diagnosis of OC [57]. In addition to peripheral blood circulating EXs, Zhou et al. (2015), using miRNAs profiling, have observed that urinary level of exosomal miR-30a-5p from ovarian serous adenocarcinoma patients was 3.3-fold higher than that in healthy women [58]. In a recent and innovative survey, researchers have analyzed circulating EXs and found diagnostic power of seven biomarkers, including HER2, EGFR, FR $\alpha, \mathrm{CA}-125$, EpCAM, CD24, and CD9 plus CD63, applying an integrated exosome profiling platform (ExoProfile chip) using only 10 $\mu \mathrm{L}$ plasma of $\mathrm{OC}$ patients. They have demonstrated that this biomarker panel obtained from molecular profiling of circulating EXs not only discriminated patient groups from benign subjects in a cohort of 20 samples but also successfully distinguished early and late-stage OC [59].

\section{BC-derived exosomal cargos and their potential role as biomarkers}

$\mathrm{BC}$ is the most common type of malignity among women. The 5-year survival rate of $\mathrm{BC}$ patients who are diagnosed in early-stage (stage I), is $100 \%$. Nevertheless, if it is diagnosed in late-stage (stage IV), the 5-year survival rate is reduced by almost $19 \%[10,60]$. Therefore, identification and development of new tools or sources for early diagnosis of cancer are urgently required. It has been shown that EXs are released from a variety of 
cancer cells, including BC $[7,61]$, therefore, breast TDEs can be used as worthwhile markers for early detection of BC. MicroRNAs-containing EXs may be considered as an ideal biomarker for early diagnosis of some diseases. Cancer-derived EXs are enriched by miRNAs compared to those released by non-tumourigenic cells [62]. On the other hand, the expression pattern of exosomal miRNAs may be correlated with the degree of tumor malignancy and prognosis [25]. In a cohort study, the levels of cellfree and exosomal miR-373, miR-372, and miR-101 in the serum of patients with different molecular subtypes of BC with healthy women have been compared. These researchers have found that the serum levels of cell-free miR-101 and miR-373 in the invasive BC were remarkably higher than $\mathrm{BC}$ benign subjects and healthy controls, but couldn't discriminate between the BC subtypes. Moreover, they have reported that exosomal miR-373 can be considered as a blood-based biomarker for more aggressive tumors, including triple-negative and hormone receptor-negative $\mathrm{BCs}$ [63]. In addition, Zhou et al. (2014) have introduced serum-derived exosomal miR-105, which is a potent regulator of cell migration through direct interaction with the tight junction protein ZO-1, as a prognostic marker for prediction of metastatic progression in patients with $\mathrm{BC}$. They have suggested that a combination of miR-105, with other blood-based miRNA and/or protein markers enhances the identification chance of $\mathrm{BC}$ patients with a high risk of metastasis [64]. In another study, using small RNA sequencing and qRT-PCR analysis of cellular and exosomal microRNAs from $\mathrm{BC}$ cell lines as well as mouse and human plasma samples, Hannafon et al. (2016) have reported that miR1246 and miR-21 are selectively enriched in human BC EXs as well as in plasma of BC PDX mice [65]. Yoshikawa et al. (2018) have found that exosomal miR-223-3p levels are significantly higher in invasive ductal carcinoma (IDC) patients, the most common type of $\mathrm{BC}$, compared to that in ductal carcinoma in situ (DCIS) BC patients and healthy controls. Their data indicated that plasma exosomal miR-223-3p levels were strongly associated with the malignancy of $\mathrm{BC}$, therefore, EXs-encapsulated miR-223-3p might be a useful preoperative biomarker for the early diagnosis of invasive BC [66]. Interestingly, Gonzalez-Villasana et al. (2019) have isolated EXs containing miR-382, miR-155, and miR-145 from the serum of both $\mathrm{BC}$ patients and healthy individuals, but not in a selective manner in patients with BC. Nevertheless, they have detected a significantly high concentration of EXs in patients with different stages of $\mathrm{BC}$ compared to healthy individuals [67].

Rupp et al. (2011) have evaluated CD24 and EpCAM as exosomal markers from ovarian carcinoma ascites, serum, and pleural effusions of $\mathrm{BC}$ patients using
anti-EpCAM or anti-CD24 magnetic beads. They have found that both EpCAM and CD24 are selectively present on cancer-derived EXs in ascites and pleural effusions, however, in BC patients EpCAM but not CD24 was absent from serum-derived EXs. These results propose that EpCAM and CD24 can be considered as suitable biomarkers for specific detection of cancer-derived EXs in ascites and pleural effusions. Moreover, they have suggested that CD24 could be an additional marker for the enrichment of TDEs which are present in the serum of breast and OC patients [68]. Wang et al. (2019) have investigated the potential application of the exosomal protein, CD82, which is one of the tetraspanin family members, in the diagnosis of $\mathrm{BC}$ patients of all stages and various histological subtypes. Their findings indicated that the expression level of CD82 was significantly down-regulated in $\mathrm{BC}$ tissue compared to that in healthy and benign breast disease tissues. Furthermore, a significant negative correlation was detected between expression levels of CD82 in tissues and EXs. This correlation is due to the redistribution of CD82 expression from tissues toward the blood with an effect on the development and metastasis of BC. Accordingly, exosomal CD82 expression levels may be useful to evaluate the metastatic potential of tumor cells and the prediction of cancer prognosis [69]. Proteomics techniques have revealed more candidate exosomal protein-based markers for early diagnosis of cancer. For instance, using liquid chromatography-tandem mass spectrometry to analyze circulating EVs isolated from plasma of BC patients (stages I and II) and healthy controls. Moon et al. (2016) have reported developmental endothelial locus-1 protein (Del-1) as a candidate exosomal protein biomarker, and mentioned that Del-1 may improve the identification of patients with early-stage $\mathrm{BC}$ in particular in combination with other diagnostic methods, such as MRI and clinicopathologic characteristics [70]. Furthermore, using mass spectrometry analyses, Melo et al. (2015) have found that glypican-1 (GPC1) is specifically enriched in cancer cellderived EXs. They have reported that the level of GPC1positive circulating EXs was increased in $75 \%$ of patients with $\mathrm{BC}$ compared to healthy individuals [71]. Although the diagnostic sensitivity of GPC1-positive EXs, as an individual biomarker for $\mathrm{BC}$, is not sufficient, it may be improved in combination with other $\mathrm{BC}$-associated exosomal markers [72]. The efficiency of applying the oncogenic protein Survivin, particularly Survivin-2B, from EXs extracted from the serum of patients with $B C$ as a diagnostic and/or prognostic marker has been confirmed by Khan et al. (2014) [73]. A growing body of evidence suggests that tumor exosomal contents particularly miRNAs and proteins reflect the stage and subtype of some tumors. For instance, Stevic et al. (2018) have evaluated 
miRNA signatures in EXs derived from HER2-positive and triple-negative (TNBC) subtypes of $\mathrm{BC}$ and compered them with exosomal miRNAs in healthy women. They detected nine miRNAs including miR-27a, miR-27b, miR-335, miR-365, miR-376c, miR-382, miR-422a, miR433, and miR-628 which differently expressed in EXs of either HER2-positive or TNBC patients compared with healthy individuals (Table 1) [74]. Moreover, Wang et al. (2019) have traced the IncRNA HOTAIR in circulatory EXs from BC patients and then investigated its pathological association with the status of the disease. Amongst diverse clinicopathological factors, a close correlation between the copy number of exosomal HOTAIR and tumoral expression of ErbB2 (HER2) has been observed, and this correlation was validated in $\mathrm{BC}$ cell lines [75]. Since molecular classification of $\mathrm{BC}$ into the different subtypes and stages is essential to select the best available treatment option and to develop new therapeutic strategies [76], identification of specific exosomal miRNAs as well as non-coding RNAs can provide novel insights into the EXs biology and its potential for monitoring the progression of disease [74]. In addition, the role of EXs in the prediction of chemotherapy-resistant $\mathrm{BC}$ has been investigated. As Yang et al. (2017) have reported for the first time, the GSTP1 content of EXs obtained from BC patients resistant to anthracycline/taxane-based chemotherapy was significantly higher than that in patients with partial or complete response to chemotherapy. Therefore, it has been suggested that GSTP1-containing EXs might be a diagnostic biomarker for chemo-resistant BC [77]. Besides, TDEs may carry cytotoxic agents with extracellular microenvironment origin and transfer them into other cells. Therefore, EXs may influence the potency and toxicity of chemotherapy agents. Barok et al. (2018) have reported a new mechanism of trastuzumab emtansine (T-DM1) that is mediated by EXs originated from HER2positive cancer cells by binding of EXs to T-DM1 and contribute to the T-DM1 activity [78]. Taken together, these reports highlight the roles of tumor-derived circulating EXs as promising biomarkers for diagnosis and prognosis of $\mathrm{BC}$, evaluation and monitoring of the therapeutic effect and outcome [25].

\section{Conclusion and future perspective}

Circulating TDEs containing TSA, and nucleic acids (especially, microRNAs) can be easily isolated using tumor markers and serve as non-invasive diagnostic and predictive biomarkers. Besides early detection, they can be used for prognosis and prediction therapeutic efficacy as well as developing metastatic disease based on their distinct molecular patterns between different stages of the disease and healthy control $[25,52]$. These subcellular nano-particles are detectable in almost all the body fluids, however, in order to gain the best results considering the cancer type, selection of a suitable isolation protocol based on the downstream analysis, type, and volume of starting sample is critical [79]. Exosome isolation/purification protocols have been designed based on different protein markers, sizes, and density. However, few of these purification methods can efficiently isolate specific types of extracellular vesicles, including EXs [80]. Traditional isolation techniques include ultracentrifugation-based techniques, immune-affinity capture-based techniques, polymeric precipitation isolation, filtration, and liquid chromatography techniques $[81,82]$. Differential centrifugation is the most widely and basic method for the separation of EXs from variety kinds of human samples. However, this technique has some restrictions such as being time-consuming, dependency on heavy equipments, losing a large number of EXs and reducing the yield and purity during the process [82]. Commercially available kits such as Invitrogen, 101Bio, Wako, and iZON may be considered as possible alternatives for quick and efficient separation of EXs from the small volume of samples [83]. To overcome some restrictions of traditional separation techniques, several novel exosome isolation methods have been recently developed. These comprise ultrafiltration separation, integrated double filtration microfluidic device, nanoplasmon-enhanced scattering (nPES), membrane-mediated exosome separation, and on-chip isolation of EXs [82]. Among all the aforementioned methods, density gradient centrifugation, chromatography (gel filtration), and nPES have been shown the most purity [82], but to eliminate the effect of normal cell EXs as well as large amount of samples and subsequently getting a high levels of pure exosome novel isolation and characterization approaches should be developed, which can be achieved via the cooperation of biology and bioengineering and the use of the Multi-Omics approaches [79]. Growing evidence suggests that EXs have the potential to be used as prognostic and early-stage diagnostic biomarkers of breast and ovarian cancers. Although, there is still a long way ahead of developing a reliable method with highspecificity for early detection of these malignancies, through the development of novel cancer-specific EXsbased screening tools, cancer prevention, and intervention strategies will be more efficient in the near future. Moreover, there is a significant need for performing large-scale clinical trials for further validation of the role of EXs as early diagnostic, predictive, and prognostic markers of breast and ovarian cancers and to evaluate their potential role in drug selection for personalized medicine. 
Table 1 Exosomal biomarkers in diagnosis and prognosis of breast and ovarian cancers

\begin{tabular}{|c|c|c|c|}
\hline Exosomal marker & Cancer type & Clinical value & References \\
\hline let-7, miR-200 & OC SKOV-3 and OVCAR-3 cell lines & $\begin{array}{l}\text { The exosomal let-7 miRNA expression was } \\
\text { significantly greater in SKOV-3 (high invasive } \\
\text { cell line) compared with OVCAR-3 (low } \\
\text { invasive cell line) } \\
\text { The expression of miR-200 family was only } \\
\text { identified in OVCAR-3 cell-derived exosomes }\end{array}$ & [84] \\
\hline miR-21, miR-23b, miR-29a & OC effusion supernatants & $\begin{array}{l}\text { High expression all three exosomal microRNAs } \\
\text { was associated with poor survival }\end{array}$ & [85] \\
\hline $\begin{array}{l}\text { miR-21, miR-141, miR-200a, miR-200b, miR- } \\
\text { 200c, miR-203, miR-205, miR-214 }\end{array}$ & OC patients serum & $\begin{array}{l}\text { Overexpression exosomal microRNAs in differ- } \\
\text { ent stages of OC patients } \\
\text { Exosomal microRNAs were significantly lower } \\
\text { in benign OC patients and negative in } \\
\text { control cases }\end{array}$ & [52] \\
\hline miR-373, miR-200a, miR-200b, miR-200c & OC patients serum & $\begin{array}{l}\text { Overexpression all four exosomal microRNAs } \\
\text { in OC patients } \\
\text { The levels of miR-200a, miR-200b, and miR- } \\
\text { 200c distinguished between malignant and } \\
\text { benign OC } \\
\text { The increased levels of miR-200c and miR- } \\
200 \mathrm{~b} \text { were associated with CA125 values and } \\
\text { shorter overall survival }\end{array}$ & [53] \\
\hline miR-99a-5p & OC patients serum & $\begin{array}{l}\text { MiR-99a- } 5 p \text { significantly elevated in OC } \\
\text { patients compared to benign patients and } \\
\text { healthy individuals }\end{array}$ & [54] \\
\hline miR-30a-5p & OC patients urine & High levels of miR-30a-5p in OC patients & [58] \\
\hline EpCAM, CD24 & OC patients ascite & High levels of EpCAM and CD24 in OC patients & [50] \\
\hline EpCAM, CD24, CA-125 & OC patients plasma & $\begin{array}{l}\text { High levels of EpCAM, CD24, and CA-125 in } \\
\text { OC patients }\end{array}$ & [51] \\
\hline $\begin{array}{l}\text { EpCAM, CD24, CA-125, HER2, EGFR, FRa, CD9, } \\
\text { CD63 }\end{array}$ & OC patients plasma & $\begin{array}{l}\text { This panel distinguished early and late stage } \\
\text { OC and discriminated patient groups from } \\
\text { benign subjects }\end{array}$ & [59] \\
\hline CD24, L1CAM, ADAM10, EMMPRIN & OC patients ascites & $\begin{array}{l}\text { Malignant ascites-derived exosomes con- } \\
\text { tained tumor progression related proteins } \\
\text { CD24, L1CAM, ADAM10, and, EMMPRIN. }\end{array}$ & [57] \\
\hline TGF- $\beta 1$, MAGE3/6 & OC patients plasma & $\begin{array}{l}\text { TGF- } \beta 1, \text { MAGE3/6 distinguished OC patients } \\
\text { from benign group and healthy controls }\end{array}$ & [55] \\
\hline Claudin-4 & OC patients plasma & High levels of Claudin- 4 in OC patients & [56] \\
\hline \multirow[t]{2}{*}{ CD24, EpCAM } & OC patients ascite & $\begin{array}{l}\text { EpCAM and CD24 were enriched in exosomes } \\
\text { from ascites and pleural effusions }\end{array}$ & [68] \\
\hline & BC patients pleural effusions and serum & EpCAM was absent from BC patients serum & \\
\hline miR-373, miR-101 & $\mathrm{BC}$ patients serum & $\begin{array}{l}\text { High levels of miR-373 and miR-101 in BC } \\
\text { patients compared to benign patients and } \\
\text { healthy individuals } \\
\text { Higher levels of miR-373 in more aggres- } \\
\text { sive tumors (triple-negative and hormone } \\
\text { receptor-negative BCs) }\end{array}$ & [63] \\
\hline miR-105 & BC patients serum & $\begin{array}{l}\text { Overexpression of miR-105 in } \mathrm{BC} \text { cells was } \\
\text { associated with high risk of metastasis }\end{array}$ & [64] \\
\hline miR-21, miR-1246 & BC patients plasma & $\begin{array}{l}\text { High levels of miR-21, miR-1246 in BC samples } \\
\text { compared to healthy subjects }\end{array}$ & [65] \\
\hline miR-223-3p & BC patients plasma & $\begin{array}{l}\text { Higher levels of miR-223-3p in IDC group com- } \\
\text { pared to DCIS patients and healthy controls }\end{array}$ & [66] \\
\hline $\begin{array}{l}\text { miR-27a, miR-27b, miR-335, miR-365, miR-376c, } \\
\text { miR-382, miR-422a, miR-433, miR-628 }\end{array}$ & BC patients plasma & $\begin{array}{l}\text { miRNAs } 27 \mathrm{~b}, 335,376 \mathrm{c}, 382 \text {, and } 433 \text { were } \\
\text { upregulated in TNBC patients } \\
\text { miRNAs } 27 \mathrm{a}, 27 \mathrm{~b}, 365 \text {, and } 628 \text { were upregu- } \\
\text { lated in HER2-positive BC patients } \\
\text { miR-422a was downregulated in HER2-positive } \\
\text { BC patients }\end{array}$ & [74] \\
\hline IncRNA HOTAIR & BC patients plasma & $\begin{array}{l}\text { Positive correlation between the exosomal } \\
\text { HOTAIR and HER2-positive BC patients }\end{array}$ & [75] \\
\hline
\end{tabular}


Table 1 (continued)

\begin{tabular}{|c|c|c|c|}
\hline Exosomal marker & Cancer type & Clinical value & References \\
\hline CD82 & BC patients plasma & $\begin{array}{l}\text { High levels of CD } 82 \text { in BC exosomes is associ- } \\
\text { ated with high risk of metastasis }\end{array}$ & {$[69]$} \\
\hline Del-1 & BC patients plasma & $\begin{array}{l}\text { Del-1 significantly elevated in BC patients } \\
\text { compared to healthy controls }\end{array}$ & {$[70]$} \\
\hline GPC1 & BC patients serum & $\begin{array}{l}\text { High levels of GPC } 1 \text { in } 75 \% \text { of } \mathrm{BC} \text { patients } \\
\text { compared to healthy individuals }\end{array}$ & {$[71]$} \\
\hline Survivin-2B & BC patients serum & $\begin{array}{l}\text { Survivin significantly elevated in BC patients } \\
\text { compared to healthy controls }\end{array}$ & {$[73]$} \\
\hline GSTP1 & BC patients serum & $\begin{array}{l}\text { GSTP1 significantly elevated in chemo-resist- } \\
\text { ant BC patients compared to chemo-sensi- } \\
\text { tivite BC group }\end{array}$ & {$[77]$} \\
\hline
\end{tabular}

OC Ovarian cancer, BC Breast cancer, IDC Invasive ductal carcinoma, DCIS Ductal carcinoma in situ, GPC1 glypican-1

\section{Authors' contributions}

LNB and SS designed the study. LNB wrote the manuscript and AAKS, FM, LM, $\mathrm{MRH}, \mathrm{SS}$, and LNB were involved in drafting the manuscript and collecting information. LNB and SS scientifically and literary supervised the manuscript. All authors read and approved the final manuscript.

\section{Funding}

None.

\section{Availability of data and materials}

The datasets reviewed during the present study are available in the Pubmed repository.

\section{Ethics approval and consent to participate}

Not applicable.

\section{Consent for publication}

Not applicable.

\section{Competing interests}

The authors have no conflict of interest.

\section{Author details}

${ }^{1}$ Department of Genetics and Molecular Biology, School of Medicine, Isfahan University of Medical Sciences, Isfahan, Iran. ${ }^{2}$ Islamic Azad University, Kazerun Branch, Kazerun, Iran. ${ }^{3}$ School of Medicine, Shiraz University of Medical Sciences, Shiraz, Iran. ${ }^{4}$ Department of Neuroscience, School of Advanced Technologies in Medicine, Tehran University of Medical Sciences, Tehran, Iran. ${ }^{5}$ Iranian National Center for Addiction Studies, Tehran University of Medical Sciences, Tehran, Iran. ${ }^{6}$ Department of Pathology, School of Veterinary Medicine, Shahrekord University, Shahrekord, Iran. ${ }^{7}$ Shiraz Molecular Pathology Research Center, Dr. Daneshbod Pathology Laboratory, Shiraz, Iran. ${ }^{8}$ Shefa Neuroscience Research Center, Tehran, Iran.

Received: 9 December 2019 Accepted: 16 May 2020

Published online: 24 May 2020

\section{References}

1. Trams EG, Lauter CJ, Salem N Jr, Heine U. Exfoliation of membrane ecto-enzymes in the form of micro-vesicles. Biochim Biophys Acta. 1981;645:63-70.

2. Edgar JR. Q \& A: what are exosomes, exactly? BMC Biol. 2016;14:46.

3. Ha D, Yang N, Nadithe V. Exosomes as therapeutic drug carriers and delivery vehicles across biological membranes: current perspectives and future challenges. Acta Pharm Sin B. 2016;6:287-96.

4. Cheng L, Wu S, Zhang K, Qing Y, Xu T. A comprehensive overview of exosomes in ovarian cancer: emerging biomarkers and therapeutic strategies. J Ovarian Res. 2017;10:73.
5. Tai YL, Chen KC, Hsieh JT, Shen TL. Exosomes in cancer development and clinical applications. Cancer Sci. 2018;109:2364-74.

6. Tang MKS, Wong AST. Exosomes: emerging biomarkers and targets for ovarian cancer. Cancer Lett. 2015:367:26-33.

7. Liu SL, Sun P, Li Y, Liu SS, Lu Y. Exosomes as critical mediators of cell-tocell communication in cancer pathogenesis and their potential clinical application. Transl Cancer Res. 2019;8:298-311.

8. Zhang Y, Liu Y, Liu H, Tang WH. Exosomes: biogenesis, biologic function and clinical potential. Cell Biosci. 2019;9:19.

9. Chen R, Xu X, Qian Z, Zhang C, Niu Y, Wang Z, et al. The biological functions and clinical applications of exosomes in lung cancer. Cell Mol Life Sci. 2019;76:4613-33

10. Porto-Mascarenhasa EC, Assada DX, Chardind H, Gozalf D, Luca Cantog GD, Acevedo AC, Guerra ENS. Salivary biomarkers in the diagnosis of breast cancer: a review. Crit Rev Oncol Hematol. 2017;110:62-73.

11. Rodriguez-Velazquez A, Velez R, Lafontaine JC, Colon-Echevarria CB, Lamboy-Caraballo RD, Ramirez I, Mendoza A, et al. Prevalence of breast and ovarian cancer subtypes in Hispanic populations from Puerto Rico. BMC Cancer. 2018;18:1177.

12. Yoneda A, Lendorf ME, Couchman JR, Multhaupt HAB. Breast and ovarian cancers: a survey and possible roles for the cell surface heparan sulfate proteoglycans. J Histochem Cytochem. 2012;60:9-21.

13. Norouzi-Barough L, Sarookhani MR, Salehi R, Sharifi M, Moghbelinejad S. CRISPR/Cas9, a new approach to successful knockdown of ABCB1/Pglycoprotein and reversal of chemosensitivity in human epithelial ovarian cancer cell line. Iran J Basic Med Sci. 2018;21:181-7.

14. Norouzi-Barough L, Sarookhani MR, Sharifi M, Moghbelinejad S, Jangjoo S, Salehi R. Molecular mechanisms of drug resistance in ovarian cancer. J Cell Physiol. 2018;233:4546-62.

15. Momenimovahed Z, Tiznobaik A, Taheri S, Salehiniya H. Ovarian cancer in the world: epidemiology and risk factors. Int J Womens Health. 2019;11:287-99.

16. Kobayashi H, Ohno S, Sasaki Y, Matsuura M. Hereditary breast and ovarian cancer susceptibility genes (Review). Oncol Rep. 2013;30:1019-29.

17. Bian X, Ma K, Zhang C, Fu X. Therapeutic angiogenesis using stem cellderived extracellular vesicles: an emerging approach for treatment of ischemic diseases. Stem Cell Res. 2019;10:158.

18. Gurunathan S, Kang MH, Jeyaraj M, Qasim M, Kim JH. Review of the isolation, characterization, biological function, and multifarious therapeutic approaches of exosomes. Cells. 2019;8:307.

19. Mao L, Li X, Yuan H, Jiang Y, Huang W, Sun X, et al. Serum exosomes contain ECRG4 mRNA that suppresses tumor growth via inhibition of genes involved in inflammation, cell proliferation, and angiogenesis. Cancer Gene Ther. 2018:25:248-59.

20. Guescini M, Genedani S, Stocchi V, Agnati LF. Astrocytes and glioblastoma cells release exosomes carrying mtDNA. J Neural Transm. 2010;117:1-4.

21. Livshts MA, Khomyakova E, Evtushenko EG, Lazarev VN, Kulemin NA, Semina SE, et al. Isolation of exosomes by differential centrifugation: theoretical analysis of a commonly used protocol. Sci Rep. 2015;5:17319. 
22. Yang C, Robbins PD. The roles of tumor-derived exosomes in cancer pathogenesis. Clin Dev Immunol. 2011. https://doi. org/10.1155/2011/842849.

23. Vlassov AV, Magdaleno S, Setterquist R, Conrad R. Exosomes: current knowledge of their composition, biological functions, and diagnostic and therapeutic potentials. Biochim Biophys Acta Gen Subj. 2012;1820:940-8.

24. Hong P, Yang H, Wu Y, Li K, Tang Z. The functions and clinical application potential of exosomes derived from adipose mesenchymal stem cells: a comprehensive review. Stem Cell Res Ther. 2019;10:242.

25. Jia Y, Chen Y, Wang Q, Jayasinghe U, Luo X, Wei Q, et al. Exosome: emerging biomarker in breast cancer. Oncotarget. 2017:8:41717-33.

26. Akers JC, Gonda D, Kim R, Carter BS, Chen CC. Biogenesis of extracellular vesicles (EV): exosomes, microvesicles, retrovirus-like vesicles, and apoptotic bodies. J Neurooncol. 2017;113:1-11.

27. Xu B, Wang T. Intimate cross-talk between cancer cells and the tumor microenvironment of B-cell lymphomas: the key role of exosomes. Tumor Biol. 2017;39:1-12.

28. Taylor DD, Gercel-Taylor C. Exosomes/microvesicles: mediators of cancerassociated immunosuppressive microenvironments. Semin Immunopathol. 2011:33:441-54.

29. Barros FM, Carneiro F, Machado JC, Melo SA. Exosomes and immune response in cancer: friends or foes? Front Immunol. 2018;9:730.

30. Xie F, Xu M, Lu J, Mao L, Wang S. The role of exosomal PD-L1 in tumor progression and immunotherapy. Mol Cancer. 2019;18:146.

31. Tian W, Liu S, Li B. Potential role of exosomes in cancer therapy. Biomed Res Int. 2019;2019:4649705.

32. Zheng H, Zhan Y, Liu S, Lu J, Luo J, Feng L, Fan S. The roles of tumorderived exosomes in non-small cell lung cancer and their clinical implications. J Exp Clin Cancer Res. 2018;37:226.

33. Kucharzewska P, Christianson HC, Welch JE, Svensson KJ, Fredlund E, Ringnér $\mathrm{M}$. Exosomes reflect the hypoxic status of glioma cells and mediate hypoxia-dependent activation of vascular cells during tumor development. Proc Natl Acad Sci. 2013;110:7312-7.

34. Wu M, Wang G, Hu W, Yao Y, Yu XF. Emerging roles and therapeutic value of exosomes in cancer metastasis. Mol Cancer. 2019;18:53.

35. Rajagopal C, Harikumar KB. The origin and functions of exosomes in cancer. Front Oncol. 2018;8:66.

36. Zhang X, Yuan X, Shi H, Wu L, Qian H, Xu W. Exosomes in cancer: small particle, big player. J Hematol Oncol. 2015;8:83

37. Azmi AS, Bao B, Sarkar FH. Exosomes in cancer development, metastasis and drug resistance: a comprehensive review. Cancer Metastasis Rev. 2013;32:623-42.

38. Li I, Nabet BY. Exosomes in the tumor microenvironment as mediators of cancer therapy resistance. Mol Cancer. 2019;18:32.

39. Sumrin A, Moazzam S, Ahmad Khan A, Ramzan I, Batool Z, Kaleem S, et al. Exosomes as biomarker of cancer. Brazilian Arch Biol Technol. 2018;61:e18160730

40. Wang Z, Chen JQ, Liu JL, Tian L. Exosomes in tumor microenvironment: novel transporters and biomarkers. J Transl Med. 2016;14:297.

41. Ye SB, Li ZL, Luo DH, Haung BJ, Chen YS, Zhang XS, et al. Tumor-derived exosomes promote tumor progression and T-cell dysfunction through the regulation of enriched exosomal microRNAs in human nasopharyngeal carcinoma. Oncotarget. 2014:5:5439-52

42. Liu Q, Yu Z, Yuan S, Xie W, Li C, Hu Z, et al. Circulating exosomal microRNAs as prognostic biomarkers for non-smallcell lung cancer. Oncotarget. 2017;8:13048-58

43. Sohn W, Kim J, Kang SH, Yang SR, Cho JY, Cho HC, et al. Serum exosomal microRNAs as novel biomarkers for hepatocellular carcinoma. Exp Mol Med. 2015;47:e184

44. Taylor DD, Homesley HD, Doellgast GJ. Membrane-associated'immunoglobulins in cyst and ascites fluids of ovarian cancer patients. Am J Reprod Immunol. 1983;3:7-11.

45. Properzi F, Logozzi M, Fais S. Exosomes: the future of biomarkers in medicine. Biomark Med. 2013;7:769-78.

46. Lugini L, Valtieri M, Federici C, Cecchetti S, Meschini S, Condello M, et al. Exosomes from human colorectal cancer induce a tumor-like behavior in colonic mesenchymal stromal cells. Oncotarget. 2016;7:50086-98.

47. Huang-Ge Z, William EG. Exosomes and cancer: a newly described pathway of immune suppression. Clin Cancer Res. 2011;17:959-64.

48. Liu X, Chan D, Ngan H. Mechanisms of chemoresistance in human ovarian cancer at a glance. Gynecol Obstet. 2012;2:1000e104.
49. Kobayashi M, Rice GE, Tapia J, Mitchell MD, Salomon C. Exosomes are fingerprints of originating cells: potential biomarkers for ovarian cancer. Res Reports Biochem. 2015;5:101-9.

50. Im H, Shao H, Park Y, Peterson VM, Castro CM, Weissleder R, Lee H. Label-free detection and molecular profiling of exosomes with a nanoplasmonic sensor Hyungsoon. Nat Biotechnol. 2014;32:490-5.

51. Zhao Z, Yang Y, Zeng Y, He M. A microfluidic exosearch chip for multiplexed exosome detection towards blood-based ovarian cancer diagnosis. Dalt Trans. 2016:16:489-96.

52. Taylor DD, Gercel-Taylor C. MicroRNA signatures of tumor-derived exosomes as diagnostic biomarkers of ovarian cancer. Gynecol Oncol. 2008;110:13-21.

53. Meng X, Müller V, Milde-Langosch K, Trillsch F, Pantel K, Schwarzenbach $H$. Diagnostic and prognostic relevance of circulating exosomal miR-373, miR-200a, miR-200b and miR-200c in patients with epithelial ovarian cancer. Oncotarget. 2016;7:16923-35.

54. Yoshimura A, Sawada K, Nakamura K, Kinose Y, Nakatsuka E, Kobayashi M, et al. Exosomal miR-99a-5p is elevated in sera of ovarian cancer patients and promotes cancer cell invasion by increasing fibronectin and vitronectin expression in neighboring peritoneal mesothelial cells. BMC Cancer. 2018;18:1056.

55. Szajnik M, Derbis M, Lach M, Patalas P, Michalak M, Drzewiecka H, et al. Exosomes in plasma of patients with ovarian carcinoma: potential biomarkers of tumor progression and response to therapy. Gynecol Obstet. 2014:4:003.

56. Li j, Sherman-baust CA, Tsai-turton M, Bristow RE, Roden RB, Morin PJ. Claudin-containing exosomes in the peripheral circulation of women with ovarian cancer. BMC Cancer. 244, 2009; 9: 244.

57. Keller S, König AK, Marmé F, Runz S, Wolterink S, Koensgen D, et al. Systemic presence and tumor-growth promoting effect of ovarian carcinoma released exosomes. Cancer Lett. 2009:278:73-81.

58. Zhou J, Gong G, Tan H, Dai F, Zhu X, Chen Y, et al. Urinary microRNA$30 a-5 p$ is a potential biomarker for ovarian serous adenocarcinoma. Oncol Rep. 2015;33:2915-23.

59. Zhang P, Zhou X, Zeng Y. Multiplexed immunophenotyping of circulating exosomes on nano-engineered ExoProfile chip towards early diagnosis of cancer. Chem Sci. 2019;10:5495-504.

60. Lässer C. Exosomal RNA as biomarkers and the therapeutic potential of exosome vectors. Expert Opin Biol Ther. 2012;12:189-97.

61. Riche A, Campbell E, Borger E, Powis S. Regulation of exosome release from mammary epithelial and breast cancer cells-a new regulatory pathway. Eur J Cancer. 2014:50:1025-34.

62. Joyc DP, Kerin MJ, Dwyer RM. Exosome-encapsulated microRNAs as circulating biomarkers for breast cancer. Int J Cancer. 2016;139:1443-8.

63. Eichelser C, Stückrath I, Müller V, Milde-Langosch K, Wikman H, Pantel $\mathrm{K}$, Schwarzenbach $\mathrm{H}$. Increased serum levels of circulating exosomal microRNA-373 in receptor-negative breast cancer patients. Oncotarget. 2014;5:9650-63.

64. Zhou W, Fong MY, Min Y, Somlo G, Liu L, Palomares MR, et al. Cancersecreted miR-105 destroys vascular endothelial barriers to promote metastasis. Cancer cell. 2014:25(4):501-15.

65. Hannafon BN, Trigoso YD, Calloway CL, Zhao D, Lum DH, Welm AL, et al. Plasma exosome microRNAs are indicative of breast cancer. Breast Cancer Res. 2016;18:90

66. Yoshikawa M, linuma $\mathrm{H}$, Umemoto $Y$, Yanagisawa T, Matsumoto A, Jinno $H$. Exosome-encapsulated microRNA-223-3p as a minimally invasive biomarker for the early detection of invasive breast cancer. Oncol Lett. 2018:15:9584-92.

67. Gonzalez-Villasana V, Rashed MH, Gonzalez-Cantú Y, Bayraktar R, Menchaca-Arredondo JL, Vazquez-Guillen JM, et al. Presence of circulating miR-145, miR-155, and miR-382 in exosomes isolated from serum of breast cancer patients and healthy donors. Dis Markers. 2019;2019:6852917

68. Rupp AK, Rupp C, Keller S, Brase JC, Ehehalt R, Fogel M, et al. Loss of EpCAM expression in breast cancer derived serum exosomes: role of proteolytic cleavage. Gynecol Oncol. 2011:122:437-46.

69. Wang X, Zhong W, Bu J, Li Y, Li R, Nie R, et al. Exosomal protein CD82 as a diagnostic biomarker for precision medicine for breast cancer. Mol Carcinog. 2019;58:658-74

70. Moon PG, Lee JE, Cho YE, Lee SJ, Jung JH, Chae YS, et al. Identification of developmental endothelial locus-1 on circulating extracellular vesicles 
as a novel biomarker for early breast cancer detection. Clin Cancer Res. 2016;22:1757-66.

71. Melo SA, Luecke LB, Kahlert C, Fernandez AF, Gammon ST, Kaye J, et al. Glypican1 identifies cancer exosomes and facilitates early detection of cancer. Nature. 2015;523:177-82.

72. Sadovska L, Eglitis J, Line A. Extracellular vesicles as biomarkers and therapeutic targets in breast cancer. Anticancer Res. 2015;35:6379-90.

73. Khan S, Bennit HF, Turay D, Perez M, Mirshahidi S, Yuan Y, Wall NR. Early diagnostic value of survivin and its alternative splice variants in breast cancer. BMC Cancer. 2014;14:176.

74. Stevic I, Müller V, Weber K, Fasching PA, Karn T, Marmé F, et al. Specific microRNA signatures in exosomes of triple-negative and HER2-positive breast cancer patients undergoing neoadjuvant therapy within the GeparSixto19 trial. BMC Med. 2018;16:179.

75. Wang YL, Liu LC, Hung Y, Chen CJ, Lin YZ, et al. Long non-coding RNA HOTAIR in circulatory exosomes is correlated with ErbB2/HER2 positivity in breast cancer. Breast. 2019;46:64-9.

76. Tsang JYS, Tse GM. Molecular classification of breast cancer. Adv Anat Pathol. 2020;27:27-35

77. Yang SJ, Wang DD, Li J, Xu HZ, Shen HY, Chen $X$, et al. Predictive role of GSTP1-containing exosomes in chemotherapy-resistant breast cancer. Gene. 2017:623:5-14.

78. Barok M, Puhka M, Vereb G, Szollosi J, Isola J, Joensuu H. Cancer-derived exosomes from HER2-positive cancer cells carry trastuzumab-emtansine into cancer cells leading to growth inhibition and caspase activation. BMC Cancer. 2018;18:504.
79. Halvaei S, Daryani S, Eslami-S Z, Samadi T, Jafarbeik-Iravani N, Oghabi Bakhshayesh T, et al. Exosomes in cancer liquid biopsy: a focus on breast cancer. Mol Ther Nucleic Acid. 2018:10:131-41.

80. Peng J, Wang W, Hua S, Liu L. Roles of extracellular vesicles in metastatic breast cancer. Breast Cancer Basic Clin Res. 2018;12:1-6.

81. Li P, Kaslan M, Lee SH, Yao J, Gao Z. Progress in exosome isolation techniques. Theranostics. 2017;7:789-804.

82. Yu LL, Zhu J, Liu JX, Jiang F, Ni WK, Qu LS, et al. A comparison of traditional and novel methods for the separation of exosomes from human samples. Biomed Res. 2018. https://doi.org/10.1155/2018/3634563.

83. Patel GK, Khan MA, Zubair H, Srivastava SK, Singh S, Singh AP. Comparative analysis of exosome isolation methods using culture supernatant for optimum yield, purity and downstream applications. Sci Rep. 2019:9:5335.

84. Kobayashi M, Salomon C, Tapia J, Illanes SE, Mitchell MD, Rice GE. Ovarian cancer cell invasiveness is associated with discordant exosomal sequestration of Let-7 miRNA and miR-200. J Transl Med. 2014;12:4.

85. Vaksman O, Tropé C, Davidson B, Reich R. Exosome-derived miRNAs and ovarian carcinoma progression. Carcinogenesis. 2014;35:2113-20.

\section{Publisher's Note}

Springer Nature remains neutral with regard to jurisdictional claims in published maps and institutional affiliations.
Ready to submit your research? Choose BMC and benefit from:

- fast, convenient online submission

- thorough peer review by experienced researchers in your field

- rapid publication on acceptance

- support for research data, including large and complex data types

- gold Open Access which fosters wider collaboration and increased citations

- maximum visibility for your research: over 100M website views per year

At BMC, research is always in progress.

Learn more biomedcentral.com/submissions 